\title{
Rapid Response for Diphtheria Control in the Dominican Republic
}

\section{To the Editors:}

Corynebacterium diphtheriae is a toxin-producing bacterium that causes respiratory or cutaneous manifestations and, without treatment, can lead to mortality. Key to diphtheria control is prevention by vaccination, which can be a challenge for health leaders in low-resource settings.

WHO reported stark differences in 2015-2016 three-dose diphtheria (DTwP) vaccine coverage rates across the island of Hispaniola, which is shared by the Dominican Republic (DR) and Haiti. In the DR, with 4 reported cases, national vaccination coverage with the third dose was estimated at $86 \%$, while almost $60 \%$ of DR municipalities reached $80 \%$ coverage.[1] In Haiti, with 37 reported cases, national third-dose coverage was estimated at $60 \%$, while almost $30 \%$ of Haitian municipalities reached $80 \%$. [1] Since the two nations share a political border, characterized by active binational commerce and cross-border movement, robust emergency preparedness for natural hazards or disease outbreaks is essential to enhance population health.

On March 27, 2018, the DR's Ministry of Public Health (MSP) mandated increased epidemiologic surveillance capacity, because of the diphtheria death of a visiting Haitian child. Vulnerable groups, such as children under five, school-aged children, health care workers, military service members, prisoners and persons with high-risk occupational exposure, have been prioritized. MSP also recommends multiple strategies to strengthen diphtheria surveillance of public and private health institutions for improved disease control: 1) strengthen capacity for early diagnosis and treatment; 2) provide health care workers with continuing education about diphtheria; 3) maintain reports and case notifications by geographic area; 4) guarantee prompt laboratory analysis of samples for case confirmation; and 5) promote clinical and epidemiological research as well as community interventions.[2]

MSP's prompt national response echoes the successful control of a DR outbreak in 2004-2005, alerting health authorities to the value of national vaccination coverage and robust surveillance programs as primary prevention strategies.[3] Strengthening DR emergency preparedness for infectious disease outbreaks requires strong political will, a national health system that prioritizes population health, and a prepared workforce for effective health service delivery. -1 -

1. World Health Organization. WHO vaccine-preventable diseases: monitoring system. 2018 global summary [Internet]. Geneva: World Health Organization; 2017 [cited 2018 Apr 8]. Available from: http://apps.who.int/immunization_mo nitoring/globalsummaryl

2. Ministry of Health (DO). Lineamientos para proteger contra la difteria poniendo al día esquema nacional de vacunación. Circular No. 000967. 22 Mar 2018. Santo Domingo: Ministry of Health (DO); 2018 Mar. Spanish.

3. Garib Z, Danovaro-Holliday MC, Tavarez Y, Leal I, Pedreira C. Diphtheria in the Dominican Republic: reduction of cases following a large outbreak. Rev Panam Salud Pública. 2015 Oct;38(4):292-9.

Bienvenido A. Veras-Estévez MD MPH (bienvenido.veras@gmail.com), Department of Epidemiology, José María Cabral y Báez Regional University Hospital, Santiago de los Caballeros, Dominican Republic.

Helena J. Chapman MD MPH PhD, College of Medicine, University of Florida, Gainesville, FL. 